\title{
Down-regulation of the expression of PKC1 and SRB 1/PSA 1/VIG9, two genes involved in cell wall integrity in Saccharomyces cerevisiae, causes flocculation
}

\author{
Nianshu Zhang, David C. J. Gardner, Stephen G. Oliver \\ and Lubomira I. Stateva
}

Author for correspondence: Lubomira I. Stateva. Tel: +44161200 4208. Fax: +441612360409.
e-mail: lubomira.stateva@ umist.ac.uk

Department of

Biomolecular Sciences,

UMIST, PO Box 88,

Manchester M60 1QD, UK

\begin{abstract}
The cell wall integrity determinants PKC1 and SRB1/PSA1/VIG9 of
Saccharomyces cerevisiae were expressed under the control of the tightly regulated promoter PMET3. Substitution of the cell-cycle-regulated SRB1/PSA1 native promoter with PMET3 led to faster cell growth, larger cell volumes, and a twofold reduction of the steady-state SRB1/PSA1 mRNA level. In addition, the new pattern of expression of SRB1IPSA1 resulted in a dominant flocculation phenotype at all phases of batch growth. By contrast, expression of PKC1 from PMET3 increased the flocculation capacity of cells only at stationary phase. Methionine-mediated repression of either PSA1/SRB1 or PKC1 resulted in enhanced cell clumping. Cells in which both these genes had been replaced with their respective pMET3-regulated cassettes were highly flocculent under both expression and repression conditions. These results suggest that greater exposure of flocculin on the cell surface, caused by either cell wall distortion (through depletion of Pkc1p) or aberrant regulation of mannosylation (through constitutive production of Srb1p), results in an increased flocculation ability.
\end{abstract}

Keywords: $M E T 3$ promoter, SRB1/PSA1, PKC1, cell wall, yeast flocculation

\section{INTRODUCTION}

The yeast cell wall is a dynamic organelle responsible for a number of cellular functions, the most important being physical and osmotic protection, selective permeability, and cell-cell recognition and adhesion during mating and flocculation (Stratford, 1994). Unlike adhesion in mating, which is induced by highly specific pheromones, flocculation is an asexual aggregation of cells which is a very useful characteristic in industrial yeast strains. Flocculation is exploited in fermentations such as beerbrewing, wine-making, and fuel ethanol production because it leads to efficient separation of cells from the fermentation liquor (Esser \& Kues, 1983).

Two types of flocculation phenotypes have been described (Stratford \& Assinder, 1991). The Flo1 type, caused by $F L O 1 / F L O 5 / F L O 8$, is $\mathrm{Ca}^{2+}$-dependent and inhibited by mannopyranoses. The NewFlo phenotype, on the other hand, is prevented by both manno- and glucopyranoses. The FLO1 gene, which is located on chromosome I, has been reported to encode a glycosylphosphatidylinositol (GPI)-anchored cell-surface protein with its amino terminus exposed to the medium (Bony et al., 1997; Straver et al., 1994). FLO5 is highly homologous to FLO1 (Bidard et al., 1994) and is also found on chromosome I. FLO8, previously mapped to chromosome I and said to be allelic to FLO1 (Teunissen et al., 1995b), has recently been reassigned to chromosome $\mathrm{V}$ and demonstrated to mediate flocculation via transcriptional activation of FLO1 (Kobayashi et al., 1996). More recently, a new flocculation gene, named FLO2, has been cloned and localized to chromosome XII; its function remains unclear, although it can complement flo1 mutations (Sieiro et al., 1997). Other genes, such as TUP1 and SNN6, also act on yeast cell flocculation via transcriptional regulation (Teunissen $e t$ al., 1995a).

Flocculation in Saccharomyces cerevisiae is thought to 
be a result of interactions between lectin-like cell-surface proteins (termed flocculins), encoded by the FLO genes, and the cell wall mannan (Miki et al., 1982; Stratford, 1992). This hypothesis is supported by the following findings: loss of flocculation capacity following protease treatment (Eddy \& Rudin, 1958; Nishihara et al., 1977, 1982), efficient dispersion of flocs by mannose and its derivatives (Mill, 1964; Taylor \& Orton, 1978), and the failure of certain $m n n$ mutant cells to co-flocculate with flocculent cells (Stratford, 1992). So far, studies of flocculation have centred on the cloning and characterization of dominant flocculation genes and the elucidation of their transcriptional regulation. Less attention has been paid to the effect of changes of cell wall structure on flocculation, although it has been found that mutations in genes that encode proteins involved in cell wall synthesis, such as KRE6 (Roemer \& Bussey, 1991) and CHS2 (Sudoh et al., 1991), may also produce a flocculent phenotype in non-flocculating strains.

The major components of the yeast cell wall are glucans and mannoproteins. Glucan consists of two polymers: a large, linear 1,3- $\beta$-glucan and a smaller, highly branched 1,6- $\beta$-glucan moiety. KRE genes, identified by killer resistance, are involved in 1,6- $\beta$-glucan synthesis (Klis, 1994). The synthesis of $1,3-\beta$-glucan is controlled by RHO1 and the PKC1 signal transduction MAP kinase pathway (Drgonova et al., 1996; Qadota et al., 1996; Cid et al., 1995). Mannoprotein, the other major cell wall component, is a complex of proteins modified by the attachment, via $\mathrm{N}$ - and O-glycosidic bonds, of mannose-containing carbohydrate chains of different length and structure. It is these carbohydrate chains that act as receptors in flocculation (Stratford, 1992). Recently, PSA1/SRB1 has been shown to encode GDPmannose pyrophosphorylase (Hashimoto et al., 1997; G. Tomlin, S. G. Oliver \& L. I. Stateva, unpublished). This enzyme produces GDP-mannose, one of the main substrates for the biosynthesis of cell wall mannoproteins and GPI anchors (Abeijon \& Hirschberg, 1992). Although PKC1 and SRB1/PSA1 may both be classified as morphogenes, they contribute to cell wall biogenesis in completely different ways. Null mutants of PKC1 can grow in the presence of osmotic stabilizers, while a SRB1/PSA1 null mutation is lethal. Loss of PKC1 function by repressing its expression while under the control of the GAL1 promoter results in a cell-cyclespecific osmotic stability defect (Levin \& BartlettHeubusch, 1992), whereas loss of SRB1/PSA1 function by inhibiting the expression of PSA1 under the control of the MET3 promoter, which depletes cells of a key substrate for protein modifications, has a very pleiotropic effect, leading to defects in bud growth, bud site selection, and cell separation, in addition to an increase in cell permeability and cell lysis (Zhang, 1997).

Here, we report that regulation of the expression of PKC1 and PSA1/SRB1 by replacing their own promoters with that of the MET3 gene, has profound effects on flocculation.

\section{METHODS}

Strains and media. The $S$. cerevisiae strains used in this study, together with their genotypes and sources, are listed in Table 1. They consist of an isogenic set. The strains were grown in minimal medium (SD) prepared by the method of Kaiser $e t$ al. (1994). Nutritional supplements were added to the medium as necessary.

Plasmids and transformation. The plasmid SRB1.9e, containing pMET3-SRB1/PSA1, is based on pRS316 (N. Zhang and others, unpublished). Yeast transformation was performed by the method of Hill et al. (1986).

Northern analysis. Yeast total RNA was extracted and separated on a $1.5 \%(\mathrm{w} / \mathrm{v})$ denaturing agarose gel according to the protocol of Kaiser et al. (1994). Following blotting onto a nylon membrane (positively charged; Boehringer Mannheim), it was hybridized with the appropriate DNA probe labelled with $\left[\alpha^{-32} \mathrm{P}\right] \mathrm{dCTP}\left(10 \mathrm{mCi} \mathrm{ml}{ }^{-1}, 1 \mathrm{Ci}=3.7 \times 10^{10} \mathrm{~Bq}\right)$ using a Rediprime kit (Amersham Pharmacia Biotech). Prehybridization, hybridization and washing steps were carried out as described by Engler-Blum et al. (1993). After washing, the membrane was wrapped in Saran-Wrap and exposed to a Bio-Rad imaging screen (type BI) which was then developed with the Bio-Rad phosphorimager (GS-363) and analysed with Molecular Analyser software (Bio-Rad).

Methionine regulation of pMET3 expression cassettes. Cultures of strains containing pMET3-regulated cassettes were grown in selective SD medium at 250 r.p.m. and $30^{\circ} \mathrm{C}$ until $\mathrm{OD}_{600} 0.05$, at which point they were split into two halves. Methionine was added to one half of each culture, to a final concentration of $2 \mathrm{mM}$; to the other half, an equivalent volume of distilled water was added. The two cultures were then incubated under the same conditions as before.

Construction of isogenic wild-type strain Z0123. Used as the control in this study, the isogenic wild-type strain was constructed by transforming a PCR product containing the $P K C 1$ gene into strain ZO124. The PKC1 coding sequence was PCR-amplified using YEplac195-PKC1 as the template, a forward primer of sequence $5^{\prime}$ GAAAGCGGCCGCAAAAGTAAGTATAGTATCAC 3', and a reverse primer of sequence $5^{\prime}$ CCTGAGCTCCAAGATAGGTACGAACAAAA $3^{\prime}$. Those transformants which could grow without $10 \%$ (w/v) sorbitol, but could not grow without a leucine supplement, were further checked for correct integration. This was done by diagnostic PCR, using one oligonucleotide, $5^{\prime}$ TGTCGATTGGTGGGCAT'TTGGG 3', which anneals to PKC1 but not the deletant sequence and another, 5' CGTCATGAACTCTCGCGGATTTGATA 3', which anneals outside the $P K C 1$ fragment. This should give a $0.85 \mathrm{~kb}$ fragment, as is the case with ZO123 (data not shown).

Construction of Z0125. ZO125 is based on ZO123 with pMET3-PSA1-LEU2 integrated at the chromosomal PSA1 locus. SRB1.9e (N. Zhang and others, unpublished) was digested with $A p a \mathrm{I}$ and Bst1107I. The fragment containing the PSA1 upstream region, $\mathrm{p} M E T 3-P S A 1-L E U 2$ and PSA1 downstream region was transformed into ZO123. The correct integration was confirmed both phenotypically (by the inability of the transformants to grow in the presence of $2 \mathrm{mM}$ methionine) and by diagnostic PCR, using primers which anneal to the MET3 promoter sequence ( $5^{\prime}$ ACGACAGAGAGAGACCCAAG $3^{\prime}$ ), and outside the MET3-PSA1-LEU2 fragment (5' CATGCTGCCTATGTTGCA $\left.3^{\prime}\right)$, respectively. 
Table 1. S. cerevisiae strains used in this study

\begin{tabular}{|c|c|c|}
\hline Yeast strains & Genotype & Source or reference \\
\hline ZO123 & MAT a bis 3 leu 2 trp1 ura 3 & This study \\
\hline ZO124 & $\begin{array}{l}\text { MATa bis3 leu } 2 \text { trp1 ura } 3 \\
p k c 1:: \text { LEU2 }\end{array}$ & D. Levin \\
\hline ZO125 & $\begin{array}{l}\text { MATa his3 leu2 trp1 ura3 } \\
\text { psa1D::pMET3-PSA1-LEU2 }\end{array}$ & This study \\
\hline ZO126 & $\begin{array}{l}\text { MATa bis3 leu2 trp1 ura3 } \\
\text { pkc1D::TRP1-pMET3-PKC1 }\end{array}$ & $\begin{array}{l}\text { N. Zhang and others, } \\
\text { unpublished }\end{array}$ \\
\hline ZO127 & 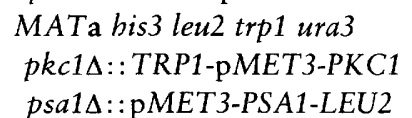 & $\begin{array}{l}\text { N. Zhang and others, } \\
\text { unpublished }\end{array}$ \\
\hline
\end{tabular}

Table 2. Flocculation tests under different conditions

\begin{tabular}{|c|c|c|}
\hline Strain and conditions & Relevant genotype & $\begin{array}{c}\text { Cells } \\
\text { flocculated } \\
(\%)\end{array}$ \\
\hline $\begin{array}{l}\text { ZO123, - Met } \\
\text { ZO123, + Met } \\
\text { ZO126, - Met } \\
\text { ZO126, + Met } \\
\text { ZO126, + Met, } 1 \mathrm{M} \text { glucose } \\
\text { ZO126, + Met, } 1 \mathrm{M} \text { mannose } \\
\text { ZO123 + FY23, - Met } \\
\text { FY23, - Met } \\
\text { ZO125, - Met } \\
\text { ZO125, - Met, } 1 \mathrm{M} \text { glucose } \\
\text { ZO125, - Met, } 1 \mathrm{M} \text { mannose } \\
\text { ZO125, + Met } \\
\text { ZO123/SRB1.9e, - Met } \\
\text { ZO127, - Met } \\
\text { ZO127, + Met }\end{array}$ & $\begin{array}{l}\text { PSA1, PKC1 } \\
P S A 1, P K C 1 \\
\text { pMET3-PKC1 } \\
\text { pMET3-PKC1 } \\
\text { pMET3-PKC1 } \\
\text { pMET3-PKC1 } \\
\\
\text { pMET3-PSA1 } \\
\text { pMET3-PSA1 } \\
\text { pMET3-PSA1 } \\
\text { pMET3-PSA1 } \\
\text { PSA1, pMET3-PSA1 } \\
\text { pMET3-PKC1, } \\
\text { pMET3-PSA1 } \\
\text { pMET3-PKC1, } \\
\text { pMET3-PSA1 }\end{array}$ & $\begin{array}{r}13 \\
15 \\
24 \\
54 \\
52 \\
0 \\
3 \\
0 \\
66 \\
60 \\
0 \\
65 \\
60 \\
97\end{array}$ \\
\hline
\end{tabular}

This diagnostic PCR amplification should result in a $1.1 \mathrm{~kb}$ band, which was exactly the case (data not shown).

The other two strains used in this study ZO126 and ZO127 (see Table 1 for genotypes) were constructed by N. Zhang and others (unpublished).

Flocculation measurements. A cell culture $(100 \mathrm{ml})$ was grown in SD medium containing $2 \%(\mathrm{w} / \mathrm{v})$ glucose for $48 \mathrm{~h}$ until stationary phase had been reached. A portion $(50 \mathrm{ml})$ of this culture was placed in a $50 \mathrm{ml}$ Falcon tube. Cells were collected by centrifugation at 5000 r.p.m. for $5 \mathrm{~min}$. The medium was poured away and cells were washed once with $250 \mathrm{mM}$ EDTA and twice with sterile water before resuspension in water to a final concentration of $1-4 \times 10^{9}$ cells $\mathrm{ml}^{-1}$. An aliquot $(1 \mathrm{ml})$ of this suspension was used for quantification of flocculation as described by Stratford \& Assinder (1991). Sugar dispersal of flocs and co-flocculation were carried out according to Stratford (1993).

\section{RESULTS AND DISCUSSION}

\section{pMET3 regulation of $P K C 1$ causes flocculation under conditions of methionine repression}

Strain ZO126 (Table 1), carrying the pMET3-PKC1 cassette, was grown until early exponential phase, when methionine $(2 \mathrm{mM})$ was added to half the culture in order to repress the expression of $P K C 1$. Incubation was then continued at $30^{\circ} \mathrm{C}$ for a further $48 \mathrm{~h}$. The other half of the culture was grown for the same time in the absence of methionine. Flocs formed in the stationary culture grown under repression conditions. Cells were harvested and flocculation was quantified as described in Methods. The wild-type strain ZO123, grown under similar conditions, with and without methionine, was included as a control. The results (Table 2) show that the wild-type cells had a very weak flocculation ability, irrespective of whether methionine was present or not. 

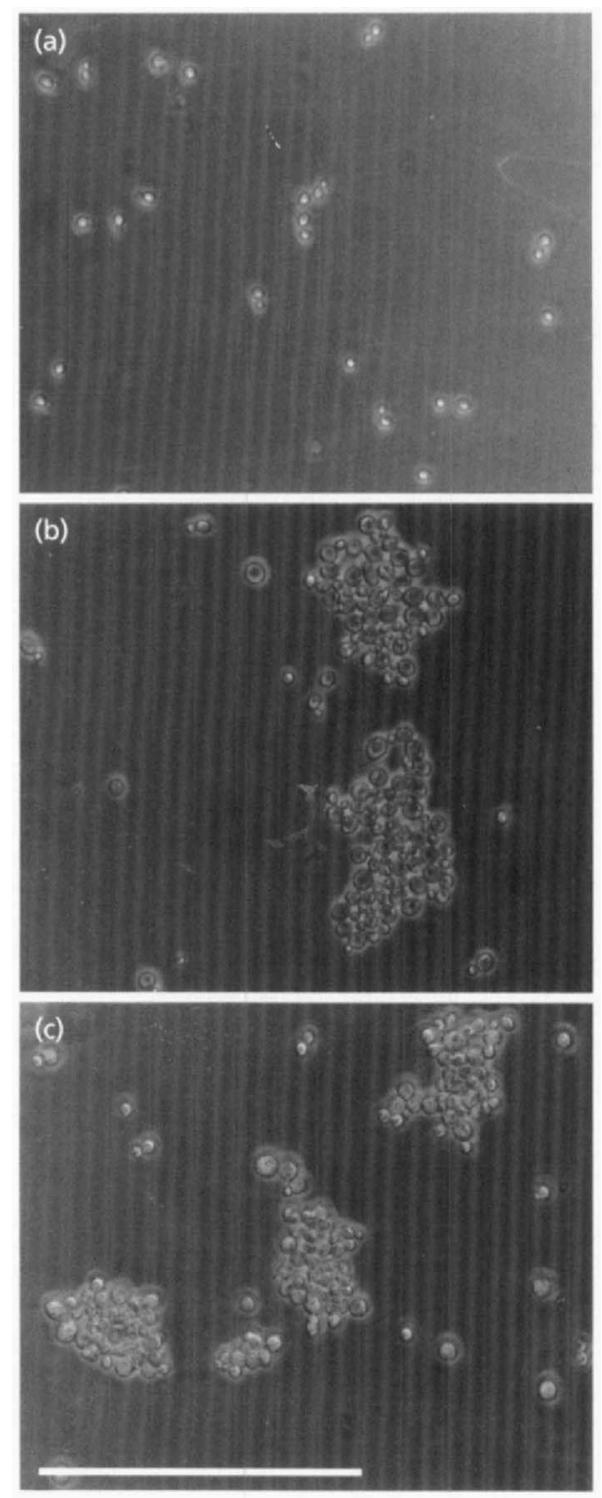

Fig. 1. Flocs of ZO125 (pMET-PSA1) and Z0123 (PSA1) transformed by SRB1.9e (pMET3-PSA1) grown under expression conditions (-Met, no methionine). Samples $(5 \mu \mathrm{l})$ of exponential-phase cultures grown under expression conditions (-Met) were pipetted onto a glass slide, covered by a cover slip and examined under a light microscope. The wild-type strain ZO123 was included as the control. (a) ZO123, (b) ZO125, (c) ZO123/SRB1.9e. Bar, $0.1 \mathrm{~mm}$.

The flocculation ability of the strain in which PKC1 is under the control of pMET3 was about $50 \%$ higher than that of the wild-type under expression (no methionine) conditions. However, this strain showed at least a three to four times greater ability to flocculate when methionine was added to repress the expression of $P K C 1$. The flocs obtained under the repression condition could be dispersed by $250 \mathrm{mM}$ EDTA and reversed by adding $\mathrm{CaCl}_{2}$, confirming that the aggregates were not induced by chain formation.

There are two types of flocculation phenotypes, Flo1 type, which can be inhibited by mannopyranoses, and
NewFlo type, which is prevented by both mannopyranoses and glucopyranoses (Stratford \& Assinder, 1991). The flocs caused by PKC1 repression could be dispersed by $1 \mathrm{M}$ mannose but not by $1 \mathrm{M}$ glucose (see Table 2), suggesting that PKC1 repression-induced flocculation belongs to the Flo1 phenotype.

$P K C 1$ has been shown to be involved in glucan biosynthesis (Cid et al., 1995). Electron micrographs of the cell wall of a temperature-sensitive $p k c 1$ mutant show that the wall loses its normal organization at the restrictive temperature. At the permissive temperature, the wall consists of an inner transparent layer and an outer, dark-stained, mannoprotein layer. By contrast, at the restrictive temperature, the transparent layer almost completely disappears and the entire wall stains dark, suggesting that the inner (skeletal) layer of the wall has been affected (Paravicini et al., 1992; Klis, 1994). Upon addition of methionine to a ZO126 culture, cells would be gradually depleted of $\mathrm{Pkc1p}$. This is expected to result in much thinner inner cell walls, which should render the mannose side-chains in the incorporated mannoprotein and/or flocculin more accessible to each other, leading to a higher ability for flocculation.

If this flocculation was induced by more exposed mannose side-chains after PKC1 was repressed, this would mean that the parent strain, ZO123, with normal PKC1 expression, would have exposed flocculin on the surface and would co-flocculate with a wild-type nonflocculent strain. To test this hypothesis, the wild-type ZO123 cells were mixed with the standard laboratory strain, FY23, which has been shown to be non-flocculent due to absence of transcription of the main flocculation gene, FLO1 (Liu et al., 1996). ZO123 and FY23 cells were washed with $250 \mathrm{mM}$ EDTA once, and with sterile water twice, and were then dispersed in $20 \mathrm{mM}$ EDTA. An approximately equal number of ZO123 and FY23 cells were suspended in flocculation buffer and flocculation was induced by adding $50 \mathrm{mM} \mathrm{CaCl}$. These two strains did not co-flocculate (Table 2), suggesting that PKC1-repressed cells are characterized by a distorted cell wall which may allow greater exposure of the flocculins on the cell surface, leading to a greater ability for flocculation. Stratford \& Carter (1993) showed that flocculins were synthesized early in cell growth, stored in the wall and activated many hours later. Flocculation could be activated artificially by a brief burst of heat, which may act by disturbing cell wall structure. Moreover, the fact that other cell wall mutants, such as kre6 (Roemer \& Bussey 1991) and chs2 (Sudoh et al., 1991), also display a flocculation phenotype supports the hypothesis that distorted cell wall exposes more flocculins on the cell surface and, as a result, enhances flocculation ability.

\section{Expression of SRB1/PSA1 under the control of the MET3 promoter causes flocculation at all stages of the batch growth cycle}

The growth of strain ZO125, harbouring the pMET3PSA1 cassette, in SD medium under expression con- 


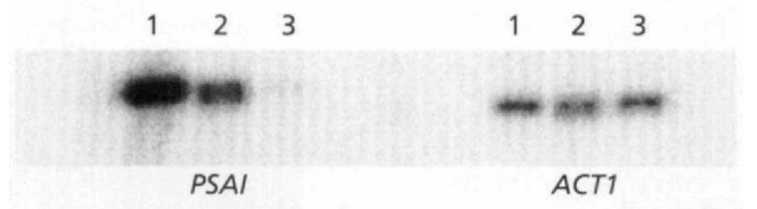

\begin{tabular}{|lcccc|}
\hline $\begin{array}{l}\text { Strain and } \\
\text { medium }\end{array}$ & $\begin{array}{c}\text { PSA1 } \\
\text { transcript }\end{array}$ & $\begin{array}{c}\text { ACT1 } \\
\text { transcript }\end{array}$ & $\begin{array}{c}\text { Ratio } \\
\text { (PSA1/ACT1) }\end{array}$ & $\begin{array}{c}\text { Wild-type } \\
\text { expression (\%) }\end{array}$ \\
\hline ZO123, -Met (1) & 64068 & 7320 & 8.76 & 100 \\
ZO125, -Met (2) & 26924 & 7180 & 3.75 & 43 \\
ZO125, +Met (3) & 415 & 6756 & 0.06 & 0.7 \\
\hline
\end{tabular}

Fig. 2. Northern analysis of PSA1 transcription in Z0125 grown under expression (-Met) or repression (+ Met) conditions; $15 \mu \mathrm{g}$ RNA from each sample was used. ACT1 was employed as the internal control. The SRB1/PSA1 transcript signal was analysed by Molecular Analyser software (signals quantified in arbitrary units) and normalized against the $A C T 1$ signal to obtain the relative transcription level.

ditions (without methionine), was characterized by the following phenotypes. The culture was 'flaky' throughout batch growth. The flocculated cells at the exponential phase are shown in Fig. 1. This suggests that the expression of SRB1/PSA1 from pMET3, unlike that of $P K C 1$ (above), leads to flocculation at any growth phase. ZO125 cells grew faster, with a doubling time of $1.9 \mathrm{~h}$ (whereas the doubling time of the wild-type strain ZO123 was $2 \cdot 1 \mathrm{~h}$ ) and appeared to have bigger cell volumes (Fig. 1), in comparison to the wild-type isogenic control, ZO123. When the cells from both strains were grown to stationary phase and subjected to the flocculation test, the cells carrying the pMET3-PSA1 expression cassette had a five times higher ability for flocculation than the control strain (Table 2).

It has recently been shown that SRB1/PSA1/VIG9 encodes the GDP-mannose pyrophosphorylase of $S$. cerevisiae (Hashimoto et al., 1997) and so is responsible for providing one of the main substrates for the glycosylation of proteins, including cell wall mannoproteins. Benton et al. (1996) also reported that the transcription of this essential gene is cell-cycle regulated, with a peak of expression occurring at the G1 phase. The flocculation phenotype accompanying the expression of SRB1/PSA1 under the control of $\mathrm{pMET3}$ could be due either to the loss of the normal cell-cycle regulation of expression, or to overexpression or underexpression. Therefore, we decided to study the level of transcription of SRB1/PSA1 from pMET3 in the absence of the repressor (methionine) and compare it with that from its native promoter. For this purpose, $\mathrm{ZO} 125$ and ZO123 were grown to mid-exponential phase and used for total RNA isolation. The RNA was subjected to standard Northern analysis, as described in Methods. As shown in Fig. 2, the transcript level of SRB1/PSA1 from the MET3 promoter is about half that from its normal promoter. These results permit us to rule out $S R B 1 / P S A 1$ overexpression as the reason for the flocculation phenotype.

\section{The flocculation phenotype caused by PMET3-PSA1 expression is dominant}

We further addressed the problem of how SRB1/PSA1 expression from the MET3 promoter caused flocculation by investigating whether pMET3-PSA1 led to flocculation in a wild-type strain. The plasmid SRB1.9e, which carries the $\mathrm{p} M E T 3-P S A 1$ cassette in a centromeric vector, was transformed into the wild-type strain ZO123, which has a wild-type copy of SRB1/PSA1 under the control of its own promoter. The transformants were grown in the same medium as that for ZO125, the strain containing an integrated copy of pMET3-PSA1 at the SRB1/PSA1 chromosomal locus. A flocculation phenotype the same as that of ZO125 was observed in all growth phases and the cell volume appeared larger compared with that of the wild-type (Fig. 1). The flocculation test, which was performed after the cells had been grown to stationary phase, showed that this transformant flocculates to the same degree as ZO125 (Table 2). This result confirmed that the flocculation phenotype caused when SRB1/PSA1 is transcribed from $\mathrm{p} M E T 3$ is not due to the gene's underexpression but, rather, is the result of its constitutive expression. When $S R B 1 / P S A 1$ is expressed from its own promoter, its transcription level increases some four- to sixfold at START (Benton et al., 1996). Thus the constitutive expression of SRB1/PSA1 from pMET3 would hyperactivate glycosylation at all other cell-cycle phases; it may well increase the expression of many genes, including flocculation genes, which in turn leads to enhanced cell growth and flocculation.

The flocs formed by constitutive SRB1/PSA1 expression could be easily dispersed by $250 \mathrm{mM}$ EDTA and reversed by adding $\mathrm{CaCl}_{2}$. Using sugars, we demonstrated (Table 2) that these flocs can only be inhibited by mannose but not by glucose, showing that this flocculation phenotype also belongs to Flo1 type. It would be interesting to determine whether the transcript levels of known FLO 
genes are up-regulated. However, it has been found that expression of pMET3-PSA1 in the non-flocculent strain FY23 did not lead to flocculation (Zhang, 1997). FY23 is a direct derivative of S288C (Winston et al., 1995), a strain that has been reported to have a nonsense mutation in FLO8 (Liu et al., 1996) that, in turn, controls the transcription of the main flocculation gene, FLO1. Taken together, our results indicate that the interaction between SRB1/PSA1 expression and the dominant flocculation genes is important in determining a flocculation phenotype.

\section{Down-regulation of SRB1/PSA1 strongly enhances flocculation}

To quantify the effect of SRB1/PSA1 repression on flocculation, ZO125 was grown under expression conditions (-Met) until early exponential phase; $2 \mathrm{mM}$ methionine was then added and the culture grown for another $48 \mathrm{~h}$ before carrying out a flocculation test. As shown in Table 2, repression of SRB1/PSA1 in ZO125 led to a fivefold increase in flocculation compared to wild-type cells. Repression or loss of SRB1/PSA1 expression has also been found to result in flocculation in a number of other circumstances. For instance, loss of a plasmid-borne copy of the wild-type SRB1/PSA1 gene from a srb1-1 host strain has been found to cause clumping (G. Hamilton \& L. Stateva, unpublished). Moreover, repression of SRB1/PSA1 expression in the standard laboratory strain FY23 causes not only cell lysis, but also flocculation (Zhang, 1997).

Srb1p/Psa1p activity results in the production of GDPmannose, an activated sugar that is involved, either directly or via the dolichol pathway, in all kinds of protein glycosylation, including GPI-anchor synthesis. The product of the dominant flocculation determinant, FLO1, has been shown to be a GPI-anchored cell-surface protein (Bony et al., 1997). Thus, it is conceivable that repression of SRB1/PSA1 results in a failure to incorporate Flo1p into the cell wall, or in its failure to function properly if incorporated. If this is the case, then the flocculation that occurs in the absence of SRB1/PSA1 expression might be due to a different mechanism to that which operates when the gene is constitutively expressed. Ballou et al. (1980) have reported that mutants, such as $m n n 9$, that lack the outer polymannose chain on their mannoproteins grow slowly and display a clumpy morphology. Thus, the flocculation resulting from SRB1/PSA1 repression could be due to a profound change in cell-surface characteristics, including hydrophobicity.

\section{Flocculation ability of a double (pMET3-PSA1, pMET3-PKC1) mutant}

Strain ZO127 (see Table 1), carrying both the pMET3PSA1 and pMET3-PKC1 cassettes, was used to test flocculation under non-repressing $(-M e t)$ and repressing $(+$ Met $)$ conditions. Under both conditions, cells from this strain formed very large flocs (Fig. 3) at all
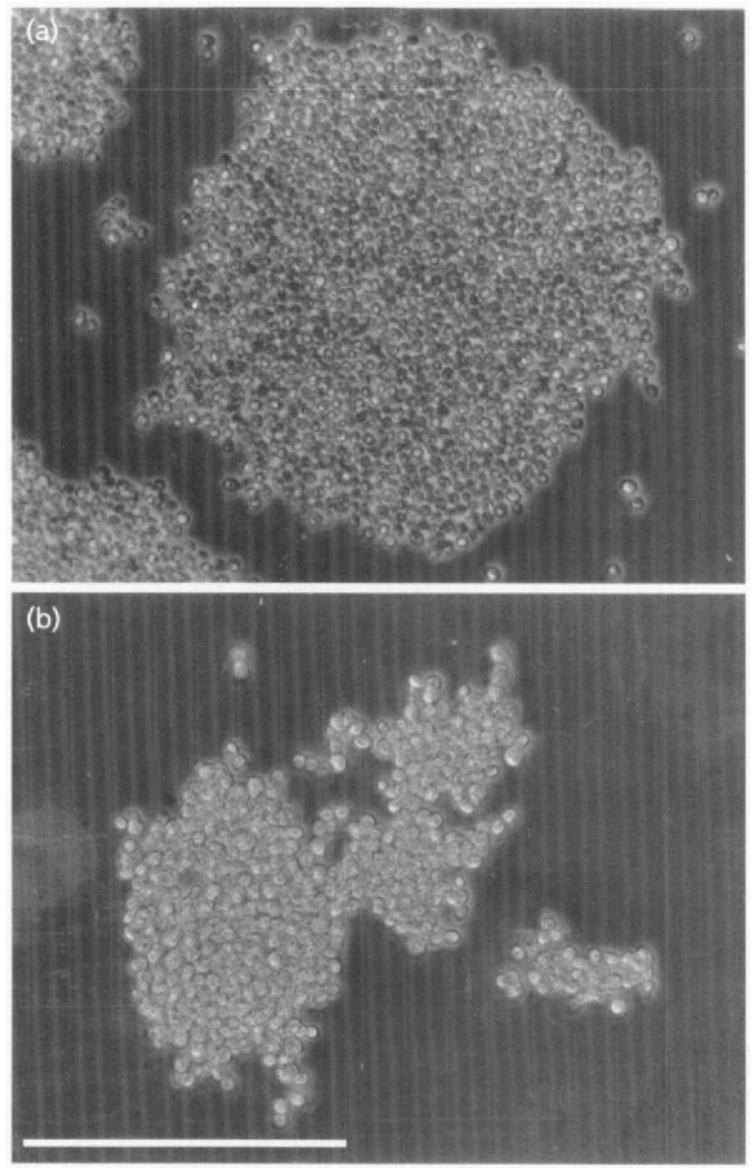

Fig. 3. Flocs of ZO127 grown under expression or repression conditions. Samples $(5 \mu \mathrm{l})$ of exponential-phase cultures grown under (a) expression ( - Met, no methionine) or (b) repression (+ Met, $2 \mathrm{mM}$ methionine) conditions were pipetted onto a glass slide, covered by a cover slip and examined under a light microscope. Bar, $0.1 \mathrm{~mm}$.

growth phases. After growth for $48 \mathrm{~h}$, cells were harvested and subjected to a flocculation test (Table 2). Around $95 \%$ of the cells, from either the - Met or the + Met culture, formed large aggregates, which could be dispersed by $250 \mathrm{mM}$ EDTA and reversed by adding $\mathrm{CaCl}_{2}$. This indicates that ZO127 cells have a higher ability for flocculation than those bearing the single cassettes (compare results in Table 2), suggesting that the flocculation effects resulting from $\mathrm{p} M E T 3$-regulated $P K C 1$ and SRB1/PSA1 expression or repression are additive.

The expression of morphogenes from their native promoters is subject to a range of controls that can regulate the synthesis of the cell wall in response to the demands of the cell cycle and the influences of stress and nutritional conditions. The replacement of the upstream regions of individual cell wall genes provides a means of investigating their dosage-dependent effects on cell wall functions, including flocculation. In this paper, we have demonstrated that regulation of PKC1 and SRB1/PSA1 
is directly linked to flocculation, one of the functions of the cell wall. These results suggest that morphogenes in yeast must obey cell-cycle controls whilst responding to environmental changes.

Flocculation provides a means of efficient separation of cells from the medium. However, most cell wall mutants with enhanced flocculation capacity are affected in cell growth or cell viability, like kre6 (Roemer \& Bussey, 1991) and $m n n 9$ (Ballou et al., 1980). The flocculation resulting from SRB1/PSA1 expression from the MET3 promoter is particularly interesting because it has no overt effect on cell growth and viability. This could be exploited to improve the flocculation ability of industrial strains. Concomitant repression of SRB1/PSA1 and $P K C 1$ leads to extensive cell lysis and flocculation (N. Zhang and others, unpublished, and the present report), making the system useful in heterologous protein expression and downstream operations in which controlled cell lysis and efficient separation of cell ghosts from the medium can be realized at the same time.

\section{ACKNOWLEDGEMENTS}

We would like to thank Harry Mountain and Peter Sudbery for providing plasmids and Andy Hayes for helping with the Northern analysis. N.Z. is also grateful for an SBFSS Award.

\section{REFERENCES}

Abeijon, C. \& Hirschberg, C. B. (1992). Topography of glycosylation reactions in the endoplasmic reticulum. Trends Biochem Sci $17,32-36$.

Ballou, L., Cohen, R. E. \& Ballou, C. E. (1980). Saccharomyces cerevisiae mutants that make mannoproteins with a truncated outer chain. J Biol Chem 255, 5986-5991.

Benton, B. K., Driscoll-Plump, S., Roos, J., Lennarz, W. \& Cross, F. (1996). Overexpression of Saccharomyces cerevisiae G1 cyclins restores the viability of alg1 $\mathrm{N}$-glycosylation mutants. Curr Genet 29, 106-113.

Bidard, F., Blondin, B., Dequin, S., Vezinhet, F. \& Barre, P. (1994). Cloning and analysis of a FLO5 flocculation gene from $S$. cerevisiae. Curr Genet 25, 196-201.

Bony, M., Thines Sempoux, D., Barre, P. \& Blondin, B. (1997). Localization and cell surface anchoring of the Saccharomyces cerevisiae flocculation protein Flo1p. J Bacteriol 179, 4929-4936.

Cid, V. J., Duran, A., Rey, F. D., Snyder, M., Nombela, C. \& Sanchez, M. (1995). Molecular basis of cell integrity and morphogenesis in Saccharomyces cerevisiae. Microbiol Rev 59, 345-386.

Drgonova, J., Drgon, T., Tanaka, K., Kollar, R., Chen, G. C., Ford, R. A., Chan, C. S. M., Takai, Y. \& Cabib, E. (1996). Rho1p, a yeast protein at the interface between cell polarization and morphogenesis. Science 272, 277-279.

Eddy, A. A. \& Rudin, A. D. (1958). Part of the yeast surface apparently involved in flocculation. J Inst Brew 64, 19-21.

Engler-Blum, G., Meier, M., Frank, J. \& Muller, G. A. (1993). Reduction of background problems in non-radioactive Northern and Southern blot analysis enables higher sensitivity than P-32 based hybridization. Anal Biochem 210, 235-244.

Esser, K. \& Kues, U. (1983). Flocculation and its implication for biotechnology. Process Biochem 18, 21-23.
Hashimoto, H., Sakakibara, A., Yamasaki, M. \& Yoda, K. (1997). Saccharomyces cerevisiae VIG9 encodes GDP-mannose pyrophosphorylase which is essential for protein glycosylation. J Biol Chem 272, 16308-16314.

Hill, J. E., Myers, A. M., Koerner, T. J. \& Tzagoloff, A. (1986). Yeast/E. coli shuttle vectors with multiple unique restriction sites. Yeast 2, 163-167.

Kaiser, C., Michaelis, S. \& Mitchell, A. (1994). Methods in Yeast Genetics. Cold Spring Harbor, NY: Cold Spring Harbor Laboratory.

Klis, F. M. (1994). Cell wall assembly in yeast. Yeast 10, 851-869. Kobayashi, O., Suda, H., Ohtani, T. \& Soe, H. (1996). Molecular cloning and analysis of the dominant flocculation gene FLO 8 from Saccharomyces cerevisiae. Mol Gen Genet 251, 707-715.

Levin, D. E. \& Bartlett-Heubusch, E. (1992). Mutants in the $S$. cerevisiae $P K C 1$ gene display a cell cycle-specific osmotic stability defect. J Cell Biol 116, 1221-1229.

Liu, H. P., Styles, C. A. \& Fink, G. R. (1996). Saccharomyces cerevisiae $\mathrm{S} 288 \mathrm{C}$ has a mutation in FLO8, a gene required for filamentous growth. Genetics 144, 967-978.

Miki, B. L. A., Poon, N. H., James, A. P. \& Seligy, V. L. (1982). Possible mechanism for flocculation interactions governed by gene FLO1 in Saccharomyces cerevisiae. J Bacteriol 150, 878-889.

Mill, P. J. (1964). The nature of the interactions between flocculent cells in the flocculation of Saccharomyces cerevisiae. J Gen Microbiol 35, 61-68.

Nishihara, H., Toraya, T. \& Fukui, S. (1977). Effect of chemical modification of cell surface components of a brewer's yeast on the floc-forming ability. Arch Microbiol 115, 19-23.

Nishihara, H., Toraya, T. \& Fukui, S. (1982). Flocculation of cell walls of brewer's yeast and effects of metal ions, protein denaturants and enzyme treatments. Arch Microbiol 131, 112-115.

Paravicini, G., Cooper, M., Friedli, L., Smith, D. J., Carpentier, J. L., Klig, L. S. \& Payton, M. A. (1992). The osmotic integrity of the yeast cell requires a functional PKC1 gene product. Mol Cell Biol 12, 4896-4905.

Qadota, H., Python, C. P., Inoue, S. B., Arisawa, M., Anraku, Y., Zhang, Y., Watanabe, T., Levin, D. E. \& Ohya, Y. (1996). Identification of yeast Rho1p GTPase as a regulatory subunit of 1,3- $\beta$-glucan synthase. Science 272, 279-281.

Roemer, T. \& Bussey, H. (1991). Yeast $\beta$-glucan synthesis: KRE6 encodes a predicted type II membrane protein required for glucan synthesis in vivo and for glucan synthase activity in vitro. Proc Natl Acad Sci USA 88, 11295-11299.

Sieiro, C., Reboredo, N. M., Blanco, P. \& Villa, T. G. (1997). Cloning of a new FLO gene from the flocculating Saccharomyces cerevisiae IM1-8b strain. FEMS Microbiol Lett 146, 109-115.

Stratford, M. (1992). Yeast flocculation: receptor definition by mnn mutants and concanavalin A. Yeast 8, 635-645.

Stratford, M. (1993). Yeast flocculation: flocculation onset and receptor availability. Yeast 9, 85-94.

Stratford, M. (1994). Another brick in the wall - recent developments concerning the yeast cell envelope. Yeast 10, 1741-1752.

Stratford, M. \& Assinder, S. (1991). Yeast flocculation: Flo1 and NewFlo phenotypes and receptor structure. Yeast 7, 559-574.

Stratford, M. \& Carter, A. T. (1993). Yeast flocculation-lectin synthesis and activation. Yeast 9, 371-378.

Straver, M. H., Smit, G. \& Kijne, J. W. (1994). Purification and partial characterization of a flocculin from brewer's yeast. Appl Environ Microbiol 60, 2745-2758. 
Sudoh, M., Shimada, H., Arisowa, M., Yano, K. \& Takagi, M. (1991). Yeast flocculation mediated by overexpression of the chitin synthase 2 gene in Saccharomyces cerevisiae. Agric Biol Chem 55, 2901-2903.

Taylor, N. W. \& Orton, W. L. (1978). Aromatic compounds and sugars in flocculation of Saccharomyces cerevisiae. J Inst Brew 84, 113-114.

Teunissen, A. W. R. H., van den Berg, J. A. \& Steensma, H. Y. (1995a). Transcriptional regulation of the flocculation genes in Saccharomyces cerevisiae. Yeast 11, 435-446.

Teunissen, A. W. R. H., van den Berg, J. A. \& Steensma, H. Y. (1995b). Localisation of the dominant flocculation genes FLO5 and FLO8 of Saccharomyces cerevisiae. Yeast 11, 735-745.

Winston, F., Dollard, C. \& Ricupero-Hovasse, S. L. (1995). Construction of a set of convenient Saccharomyces cerevisiae strains that are isogenic to S288C. Yeast 11, 53-55.

Zhang, N. (1997). Genetically-controlled cell lysis in yeast Saccharomyces cerevisiae. PhD thesis, UMIST.

Received 30 July 1998; revised 28 September 1998; accepted 15 October 1998. 